\title{
Fenologia do estrato herbáceo-subarbustivo de uma comunidade de campo sujo na Fazenda Água Limpa no Distrito Federal, Brasil ${ }^{1}$
}

\author{
Cássia Beatriz Rodrigues Munhoz ${ }^{2,4}$ e Jeanine Maria Felfili ${ }^{3}$
}

Recebido em10/12/2002. Aceito em 13/06/2005

\begin{abstract}
RESUMO - (Fenologia do estrato herbáceo-subarbustivo de uma comunidade de campo sujo na Fazenda Água Limpa no Distrito Federal, Brasil). O objetivo deste trabalho foi avaliar a influência das mudanças sazonais sobre a fenologia vegetativa (foliação) e reprodutiva (floração e frutificação) do componente herbáceo-subarbustivo de uma comunidade de campo sujo (1555'478'S e 4754'225"'W) na Fazenda Água Limpa, Brasília, DF. O clima da região é do tipo Aw, segundo a classificação de Köppen, com precipitação média anual de $1.500 \mathrm{~mm}$. Foram selecionados 3 a 10 indivíduos de 61 espécies distribuídas em 23 famílias, resultando em 519 indivíduos marcados. Os indivíduos foram observados quinzenalmente, de outubro/1999 a fevereiro/2001. O fogo ocorrido na área dois meses antes do início do estudo estimulou a floração e a frutificação das espécies amostradas. A floração na comunidade apresentou-se distribuída por todo o período estudado, com concentração na estação chuvosa. O período de produção de frutos foi similar ao de produção de flores e a maioria das espécies amadureceu seus diásporos do meio da estação chuvosa até o fim da seca. Na estação seca houve grande percentagem de espécies com folhas secas. No entanto, nem todas as espécies secaram completamente suas folhas nesse período, sendo que 3,2\% produziram folhas novas e $31 \%$ mantiveram suas folhas verdes. Os eventos vegetativos e reprodutivos das plantas da camada herbáceosubarbustiva mostraram-se dependentes da pluviosidade.
\end{abstract}

Palavras-chave : fenologia, estrato herbáceo, campo sujo, cerrado, fogo

\begin{abstract}
Phenology of the herbaceous layer in a campo sujo community in the Fazenda Água Limpa, Federal District, Brazil). The objective of this study was to analyse the phenological events in the herbaceous and sub-shrub layer of a campo sujo (15 $55^{\prime} 478^{\prime \prime} \mathrm{S}$ and $47^{\circ} 54^{\prime} 225^{\prime} \mathrm{W}$ ) community in relation to rainfall. The climate is Aw by Köppen classification with a mean annual precipitation of 1,500 $\mathrm{mm}$. Three to ten individuals belonging to 61 species were studied totaling 519 individuals. The individuals were observed quarterly, from October 1999 to February 2001. An accidental fire happened in the area two months before the beginning of this study. It stimulated flowering and fruiting of the species. Flowering occurred continuosly over the study period but, with a concentration in the rainy season. Fruiting presented a similar pattern with most species maturing their diaspores from the middle to the end of the rainy season. During the dry season there was a higher production of dry leaves. However, some species did not have all leaves completely dried in that period, $3.2 \%$ produced new leaves while $31 \%$ remained with mature green leaves. The vegetative and reproductive events of the plants in the herbaceous layer were dependent on the precipitation.
\end{abstract}

Key words: phenology, herbaceous layer, campo sujo, Cerrado, fire, savanna, Brazil

\section{Introdução}

Estudos com espécies tropicais sugerem que os padrões fenológicos das árvores em geral são influenciados por vários fatores, como regime de chuvas, irradiação, temperatura (Alvin 1967; Daubenmire 1972; Frankie et al. 1976; Monasterio \& Sarmiento 1976; Sarmiento 1983; Sarmiento \& Monasterio 1983; Reich \& Borchert 1984; Rathcke \& Lacey 1985; Silva 1987; Schaik et al. 1993; Seghieri et al. 1995) e atividade de polinizadores e dispersores
(Janzen 1967; Frankie et al. 1974; Rathke \& Lacey 1985).

Segundo Borchert (1999), a sazonalidade das chuvas com um período seco prolongado é o determinante climático primário da fenologia foliar. A forte sazonalidade do Cerrado, com verões chuvosos e invernos secos, vem sendo alvo de investigações sobre o padrão da fenodinâmica exibido por espécies vegetais individuais e, para grupos de espécies congenéricas de porte arbóreo-arbustivo (Barros \& Caldas 1980; Ribeiro et al. 1982; Gottsberger 1986;

\footnotetext{
1 Parte da tese de Doutorado da primeira Autora. Bolsista CAPES

2 Universidade Católica de Brasília, Curso de Ciências Biológicas, QS 07 Lote 01, Bloco M, Sala 206, CEP 72030-170, Taguatinga, DF, Brasil

3 Departamento de Engenharia Florestal, Universidade de Brasília, C. Postal 04357, CEP 70919-970, Brasília, DF, Brasil

4 Autor para correspondência: cassia@ucb.br
} 
Batalha et al. 1997; Madeira \& Fernandes 1999) e para comunidades (Mantovani \& Martins 1988; Oliveira 1994; 1998; Oliveira \& Moreira 1992; Miranda 1995; Gouveia \& Felfili 1998; Batalha \& Mantovani 2000). Entretanto, são ainda escassas publicações que contemplem a fenologia do estrato herbáceo-subarbustivo (Mantovani \& Martins 1988; Almeida 1995; Batalha et al. 1997; Batalha \& Mantovani 2000).

Oliveira (1998), estudando a biologia reprodutiva do cerrado, concluiu que os padrões fenológicos de plantas lenhosas parecem ser independentes das restrições sazonais, pelo menos no caso dos processos reprodutivos. Felfili et al. (1999) encontraram uma correlação positiva entre a precipitação e todos os eventos fenológicos estudados em Stryphnodendron adstringens (Mart.) Cov., uma espécie arbórea de cerrado.

A fenologia das ervas graminóides das savanas tropicais é analisada como uma adaptação à sazonalidade desses ecossistemas (Sarmiento 1984). Para as plantas do estrato herbáceo-subarbustivo, que possuem sistemas subterrâneos superficiais e, portanto, sofrem restrições hídricas, a seca afeta sua fenologia (Mantovani \& Martins 1988; Batalha et al. 1997; Batalha \& Mantovani 2000). Esses estudos mostraram que há acentuada diminuição na floração na estação seca, especialmente nos meses de junho a agosto, e concentração de espécies florescendo na estação chuvosa, com pico ocorrendo nos meses de janeiro a abril.

A competição entre a demanda de recursos para investimentos em estruturas vegetativas e reprodutivas pode influenciar o ciclo de vida das espécies de uma comunidade vegetal (Sarmiento \& Monasterio 1983). $\mathrm{O}$ entendimento das formas de vida das espécies do estrato herbáceo-subarbustivo do cerrado e suas manifestações fenológicas está condicionado à produção de conhecimento sobre a distribuição espacial e temporal das espécies e suas relações com os fatores ambientais. Faltam dados quantitativos sobre a representatividade das espécies ao longo do ano em função das formas de vida da comunidade e das suas manifestações fenológicas.

O objetivo deste trabalho foi avaliar a influência dos padrões de pluviosidade sobre a fenologia vegetativa (foliação) e reprodutiva (floração e frutificação) do componente herbáceo-subarbustivo em uma comunidade de campo sujo. Partiu-se da premissa que a fenologia vegetativa e reprodutiva das espécies da camada herbáceo-subarbustiva de campo sujo é definida pela forte sazonalidade da região.

\section{Material e métodos}

Este estudo foi realizado no período de outubro/1999 a fevereiro/2001 na Fazenda Água Limpa, situada ao sul do Distrito Federal, área núcleo da Reserva da Biosfera do Cerrado. O campo sujo estudado ocupa uma área de 16 ha próxima a mata de

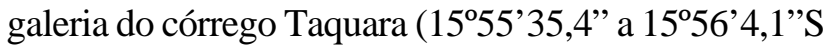
e $47^{\circ} 54^{\prime} 20,8^{\prime \prime}$ a $47^{\circ} 54^{\prime} 21,9^{\prime \prime}$ WGr.) a $1.050 \mathrm{~m}$ de altitude. A área sofreu uma queimada acidental na primeira semana de agosto/1999.

O clima da região é do tipo Aw, segundo a classificação de Köppen, e caracteriza-se por duas estações bem definidas: uma quente e chuvosa, de outubro a abril, e outra fria e seca, de maio a setembro. A temperatura média máxima é de $28,5^{\circ} \mathrm{C}$ e a média mínima de $12,0^{\circ} \mathrm{C}$. A média anual de precipitação no período estudado foi de $1.500 \mathrm{~mm}$. Os dados climáticos para o período deste estudo foram coletados na estação meteorológica do Reserva Ecológica do Instituto Brasileiro de Geografia e Estatística distante $5 \mathrm{~km}$ da área de estudo (Fig. 1).

No campo sujo próximo à mata de galeria do córrego Taquara foi selecionada uma área de $400 \times 400 \mathrm{~m}$ que foi sub-dividida em quatro porções de $200 \times 200$. Em cada porção sorteou-se uma linha de $40 \mathrm{~m}$ perpendicular à borda da mata onde foram efetuados inventários fitossociológicos (C.B.R. Munhoz, dados não publicados). Para o estudo fenológico foram selecionadas espécies que possuíam de três a dez indivíduos distantes no mínimo a $1 \mathrm{~m}$ e no máximo a $10 \mathrm{~m}$ das linhas marcadas para os estudos fitossociológicos. Para as espécies da camada herbácea, principalmente ervas graminóides, a separação de indivíduos é muito difícil. Assim, optou-se por marcar cada um distante pelo menos $3 \mathrm{~m}$ do seu vizinho

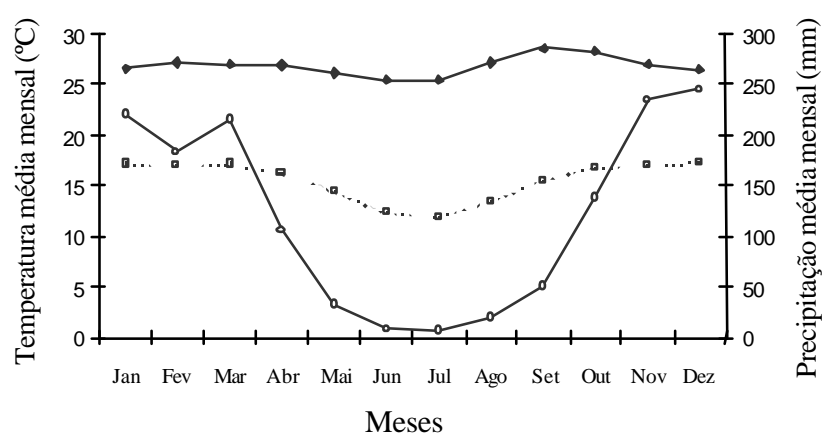

Figura 1. Valores médios de precipitação e máximos e mínimos de temperatura, medidos nos anos de 1980 a 2001 na Estação Meteorológica da Reserva Ecológica do Instituto Brasileiro de Geografia e Estatística, DF, Brasil. --"-- = Temp. Média Min.; $-\bullet-=$ Temp. Média Max.; -o- Precipitação. 
coespecífico, para evitar a marcação de expansões radiculares de um mesmo indivíduo (ramets).

Foram marcados apenas indivíduos com hábito herbáceo-arbustivo, segundo a classificação das formas de vida das espécies proposta por Eiten (1992), contemplando as seguintes categorias: 1 - arbusto, planta lenhosa de até $2 \mathrm{~m}$ alt.; 2 - subarbusto, planta com caule lenhoso na parte basal e herbáceo na distal e 3 - erva, planta com caule completamente herbáceo.

Os indivíduos foram observados de 15 em 15 dias, tendo sido registrados a presença e ausência das seguintes fenofases: floração ( 1 - botões e 2 - flores abertas), frutificação (1 - frutos imaturos; e 2 - frutos maduros, presentes ou dispersando) e mudança foliar (1 - folhas novas; 2 - folhas maduras, verdes; e 3 - folhas secas).

Foram efetuadas correlações de Spearman entre as fenofases e a pluviosidade para a comunidade (Sokal \& Rohlf 1981). As variáveis número de indivíduos e número de espécies, apresentando o evento por quinzena, foram usadas para a análise.

\section{Resultados}

No campo sujo da Fazenda Àgua Limpa foram estudados 519 indivíduos herbáceos-subarbustivos, distribuídos em 61 espécies e 23 famílias (Tab. 1).

Floração - A floração na comunidade de campo sujo apresentou-se distribuída por todo o período estudado, com concentração de espécies florescendo na estação chuvosa. Após a ocorrência do fogo, observou-se a maior percentagem de espécies florescendo, chegando a $37 \%$ das espécies com flores no mês de novembro/1999, sendo quase duas vezes maior do que a encontrada no ano seguinte no mesmo período com semelhante pluviosidade, quando não se registraram queimadas (Fig. 2A). O mesmo pode ser verificado em relação ao número de indivíduos estudados, mas com diferenças ainda mais pronunciadas. Enquanto, em novembro/1999 foram observados $23 \%$ de indivíduos com flores abertas, para o mesmo período de 2000 encontraram-se apenas 3\% (Fig. 2B).

A floração das espécies do estrato herbáceosubarbustivo no campo sujo amostrado esteve relacionada com as chuvas. O coeficiente de correlação de Spearman entre a precipitação e a emissão de flores abertas foi significativo $(\mathrm{p}<0,05)$, para as espécies $\left(\mathrm{r}_{\mathrm{s}}=0,55 ; \mathrm{p}=0,001\right)$ e os indivíduos $\left(\mathrm{r}_{\mathrm{s}}=0,45 ; \mathrm{p}=0,01\right)$ (Tab. 2). Foram encontrados dois picos de floração na comunidade: de novembro a março no auge da estação úmida, no período que sucedeu à queimada, e de setembro a novembro, no início da estação úmida do ano de 2000, um ano após o fogo registrado na área (Fig. 2A, B). Espécies como Ruellia brevicaulis, Aspilia foliacea, Riencourtia oblongifolia, Ipomoea campestris, Ipomoea procurrens, Erythroxylum campestre e Mimosa lanuginosa, retardaram o período de floração após o fogo (Tab. 1). Essa última, por exemplo, floresceu entre janeiro e abril/2000 e depois entre julho e outubro do mesmo ano. Croton goyazensis e Polygala tenuis apresentaram dois picos de floração na mesma estação úmida, e outro, também, na estação seca, após a ocorrência de uma chuva na área (Tab. 1). Isto demonstra que algumas espécies do estrato herbáceo-subarbustivo florescem mais de uma vez por ano.

A seca não restringiu completamente a emissão de botões florais na área estudada. Nos meses de junho e agosto 14,7 e $4,9 \%$ das espécies, respectivamente, e 8,1 e $4,9 \%$ dos indivíduos amostrados apresentaram o evento.

O coeficiente de correlação de Spearman entre a precipitação e emissão de botões florais na comunidade mostrou uma relação direta, porém não significativa para o total de indivíduos $\left(\mathrm{r}_{\mathrm{s}}=0,19 ; \mathrm{p}=0,28\right)$ e de espécies $\left(r_{s}=0,19 ; p=0,30\right)$ amostrados no campo sujo (Tab. 2). A emissão de botões florais, após a ocorrência do fogo, foi maior no mês de dezembro de 1999, chegando a 23\%, enquanto no ano seguinte, quando não se registraram queimadas, a maior taxa foi registrada no mês de outubro, com $25 \%$ das espécies com emissão de botões florais (Fig. 2A). O número de indivíduos com botões foi maior nos meses de novembro e dezembro/1999, quando foram observados $15 \%$ de indivíduos com botões, para o ano de 2000 o pico de produção de botões atingiu apenas $7 \%$ no final do mês de setembro, início da estação chuvosa (Fig. 2B).

Frutificação - A produção de frutos novos foi maior no período chuvoso, entre os meses de dezembro a março, e a maioria das espécies amadureceram seus frutos do meio da estação chuvosa até a estação seca, entre os meses de janeiro e julho (Fig. 3A). A maior taxa de espécies frutificando foi observada em dezembro/1999, chegando a $37 \%$ de produção de frutos novos, enquanto que um ano depois a percentagem caiu para $6,5 \%$. De junho/2000 a janeiro/2001 o número de indivíduos com frutos imaturos reduziu drasticamente em relação aos nove meses anteriormente estudados, o que é resultado da diminuição no número de espécies e, principalmente, ao número de indivíduos com frutos jovens durante a 


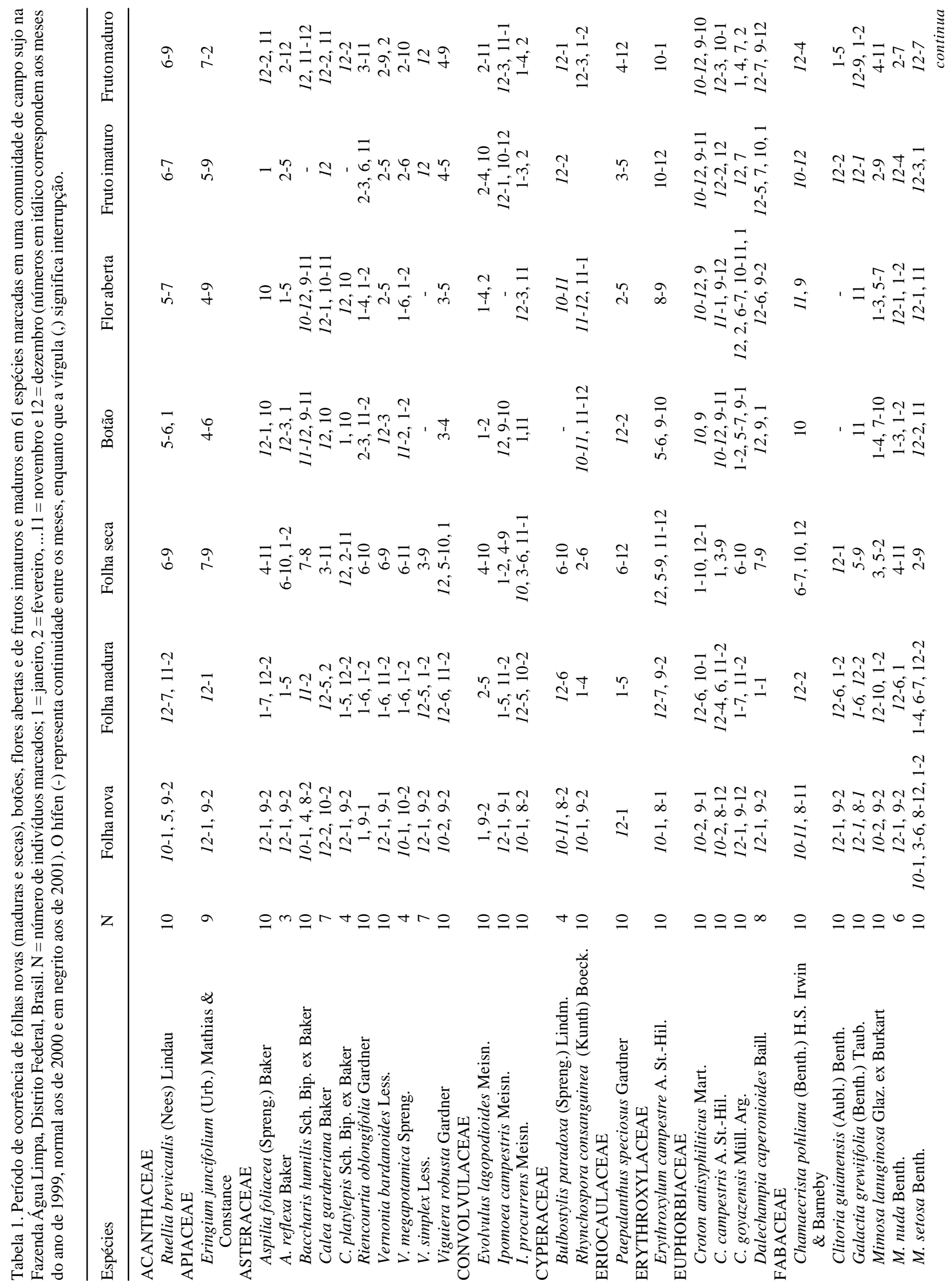




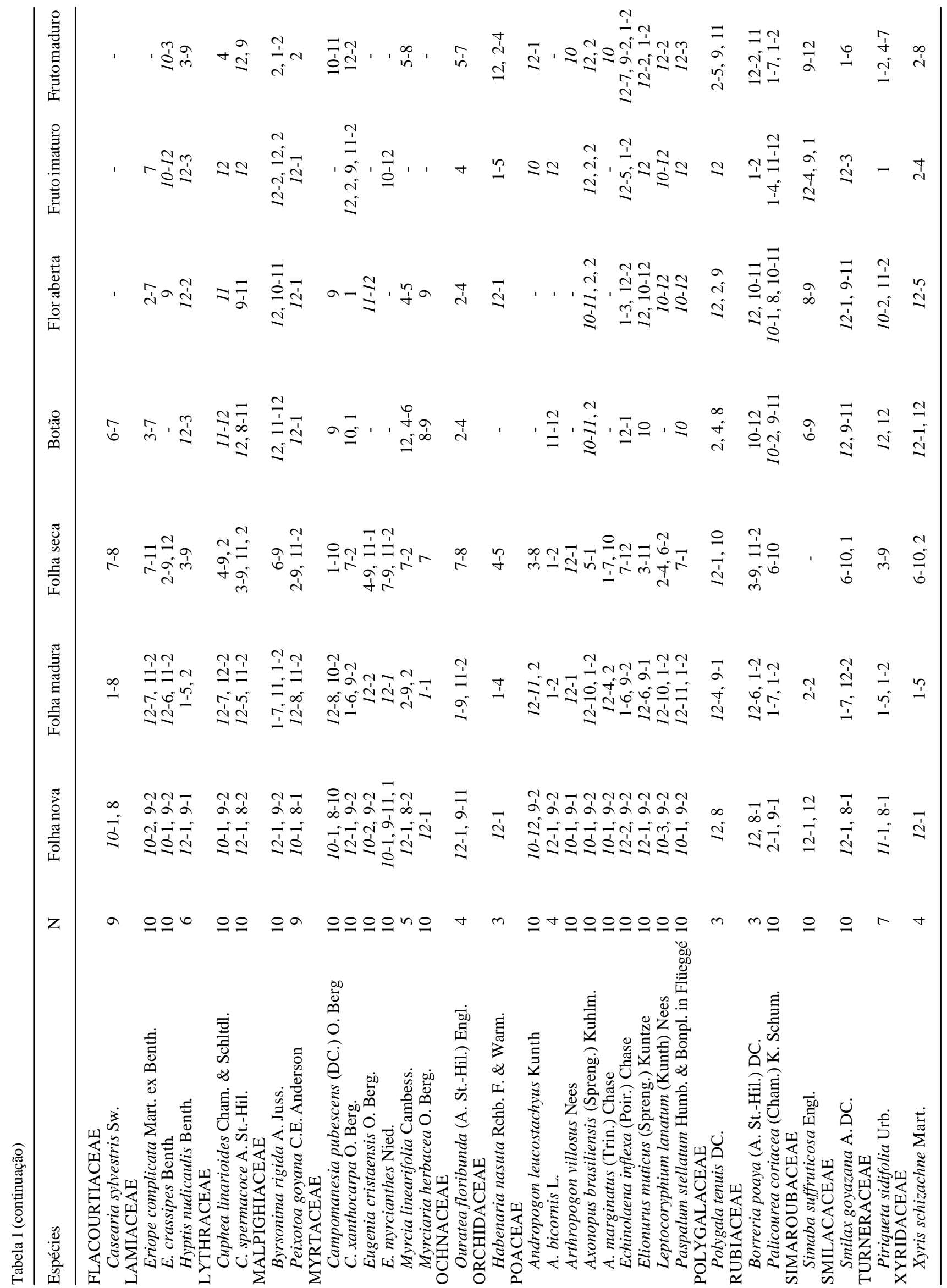


Tabela 2. Coeficientes de correlação de Spearman entre a precipitação mensal e as fenofases reprodutivas (flor nova e aberta, fruto imaturo e maduro) e vegetativas (folha nova, madura e seca), para o total de indivíduos e espécies em uma comunidade de campo sujo na Fazenda Água Limpa, Distrito Federal, Brasil.

\begin{tabular}{lcc}
\hline Fenofase & Indivíduos & Espécies \\
\hline Botão & $0,19(\mathrm{p}=0,28)$ & $0,19(\mathrm{p}=0,30)$ \\
Flor Aberta & $0,45^{*}(\mathrm{p}=0,01)$ & $0,55^{*}(\mathrm{p}=0,002)$ \\
Fruto Imaturo & $0,21(\mathrm{p}=0,24)$ & $0,48^{*}(\mathrm{p}=0,007)$ \\
Fruto Maduro & $-0,51^{*}(\mathrm{p}=0,004)$ & $-0,16(\mathrm{p}=0,38)$ \\
Folha Nova & $0,44^{*}(\mathrm{p}=0,01)$ & $0,39^{*}(\mathrm{p}=0,03)$ \\
Folha Madura & $-0,16(\mathrm{p}=0,36)$ & $0,02(\mathrm{p}=0,92)$ \\
Folha Seca & $-0,61^{*}(\mathrm{p}=0,0007)$ & $-0,67^{*}(\mathrm{p}=0,0002)$ \\
\hline
\end{tabular}

* Significativo $\mathrm{p}<0,05$

estação seca e ao fato de que a produção de frutos ter sido muito maior no período que sucedeu ao fogo (Fig. 3B).

Foi observada uma alta taxa de espécies com frutos maduros ao longo de todo ano, com diminuição no início da estação úmida, entre os meses de setembro e novembro (Fig. 3A). A correlação entre os indivíduos com frutos maduros e a precipitação foi inversa e significativa $\left(\mathrm{r}_{\mathrm{s}}=-0,51 ; \mathrm{p}=0,004\right)$, devido à permanência dos frutos maduros na planta na estação seca, em espécies como Vernonia bardanoides, Vernonia megapotamica, Galactia grewiifolia, Mimosa setosa, Hyptis nudicaulis e Echinolaena inflexa (Tab. 1). No mês de agosto o número de espécies com frutos maduros permaneceu alta $24,6 \%$ das espécies e 12,3\% dos indivíduos (Fig. 3A).

Mudança foliar - no campo sujo estudado foi observado um pico anual de espécies emitindo folhas novas, com 95\% em dezembro/1999, ano em que ocorreu o incêndio; e 95\% entre outubro e novembro/2000, logo no início das chuvas (Fig. 4A). Porém, quanto ao número de indivíduos houve uma redução no segundo ano, com $89 \%$ dos indivíduos com folhas novas em dezembro/1999 e 74\% em novembro/2000 (Fig. 4B).

Aproximadamente 3,2\% das espécies e 1,8\% dos indivíduos do estrato herbáceo-subarbustivo produziram folhas novas no início ou no fim da estação seca (Fig. 4), entre elas Ruellia brevicaulis, Baccharis humilis, Ipomoea procurrens e Mimosa setosa (Tab. 2). No campo sujo da Fazenda Água Limpa algumas espécies, entre elas Arthropogon villosus, Axonopus brasiliensis,
A

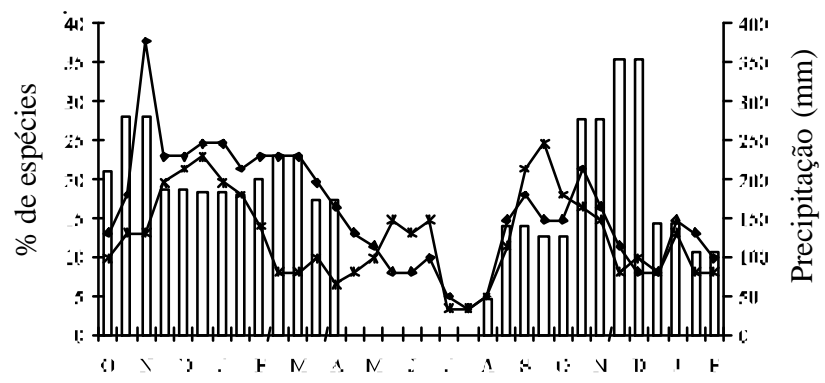

B

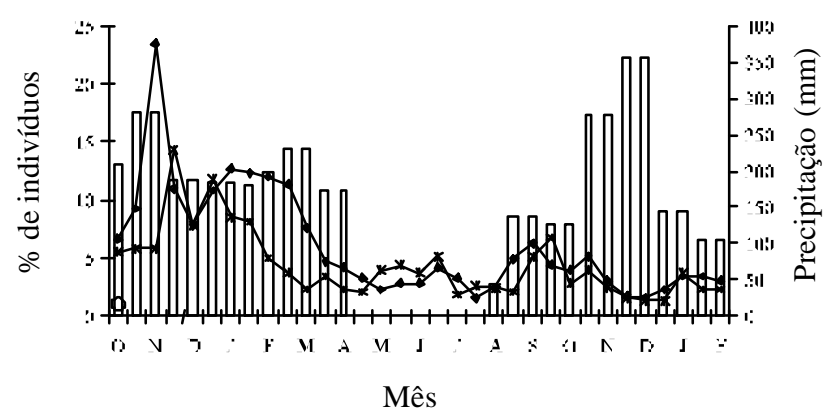

Figura 2. Variação quinzenal durante 17 meses da floração de espécies (A) e indivíduos (B) em uma comunidade de campo sujo na Fazenda Água Limpa, DF, Brasil. $\square=$ Precipitação; $-*-=$ Botão; $-\bullet-=$ Flor aberta.
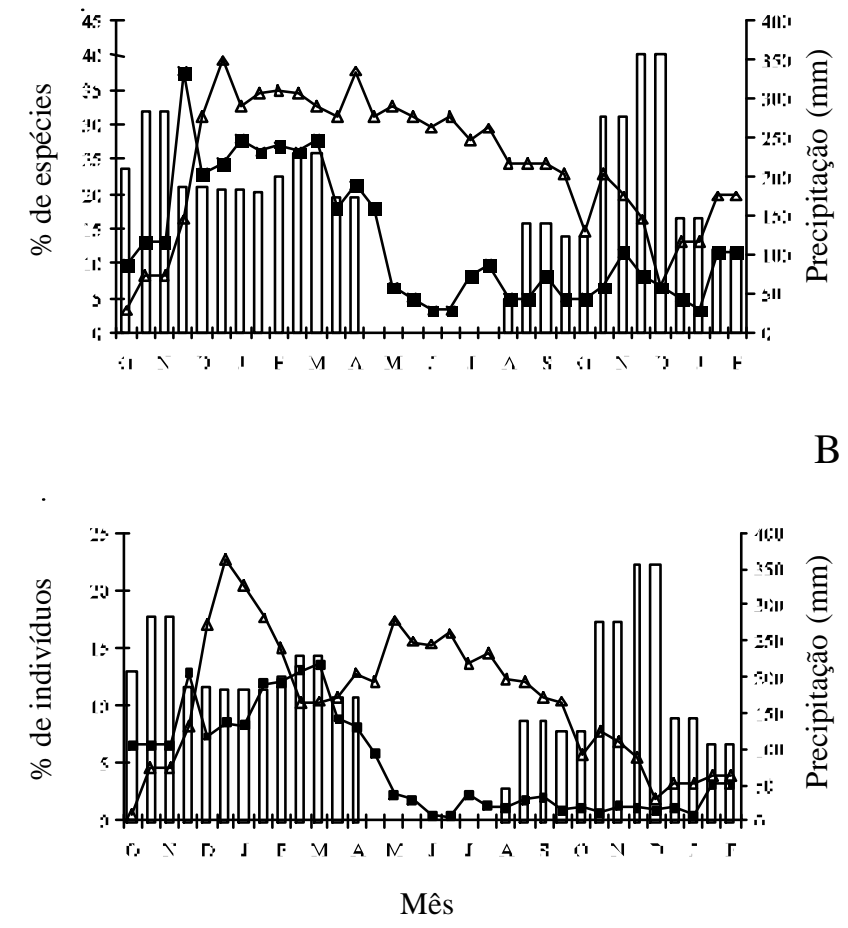

Figura 3. Variação quinzenal durante 17 meses da frutificação de espécies (A) e indivíduos (B) em uma comunidade de campo sujo na Fazenda Água Limpa, DF, Brasil. $\square=$ Precipitação; - - $-=$ Fruto imaturo; $\triangle-=$ Fruto maduro. 


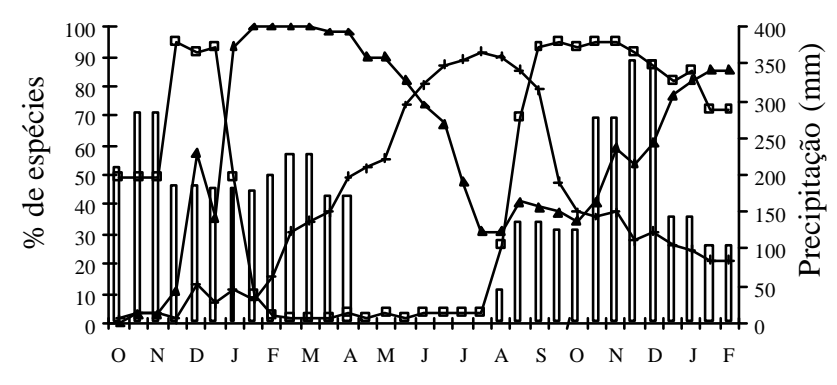

B

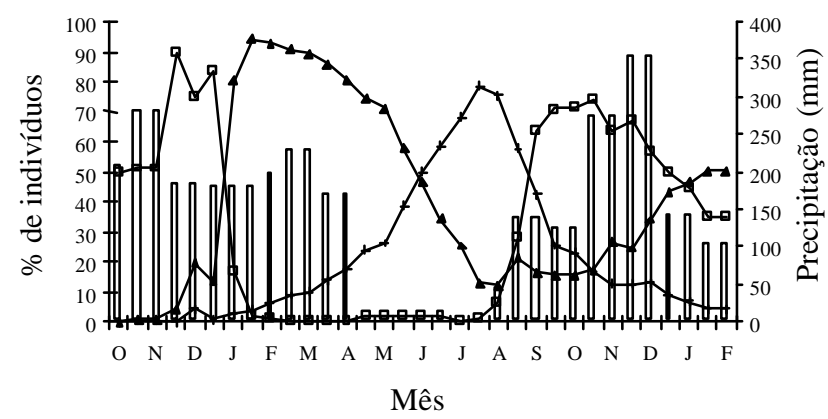

Figura 4. Variação quinzenal durante 17 meses da folhação de espécies (A) e indivíduos (B) em uma comunidade de campo sujo na Fazenda Água Limpa, DF, Brasil. $\square=$ Precipitação; $-\square=$ = Folha nova; $+=$ Folha seca.

Leptocoryphium lanatum, Simaba suffruticosa, Eugenia cristaensis e Ouratea floribunda, mantiveram parte de suas folhas verdes (maduras) por um longo período, perfazendo $31 \%$ das espécies e $12 \%$ dos indivíduos amostrados (Fig. 4A, B).

A correlação entre precipitação e folhas secas foi inversa e significativa, tanto para o número de indivíduos quanto para número de espécies $\left(\mathrm{r}_{\mathrm{s}}=-0,61\right.$; $\mathrm{P}(0,0007))$ e $\left(\mathrm{r}_{\mathrm{s}}=-0,67 ; \mathrm{P}(0,0002)\right)$. A fase mais intensa de registro de folhas secas foi observada no final do mês de julho, quando $91,8 \%$ das espécies e $78 \%$ dos indivíduos apresentavam o evento.

\section{Discussão}

Os coeficientes de correlação de Spearman significativos para a relação da precipitação com os eventos fenológicos flores abertas e emissão de folhas novas, tanto para as espécies como para os indivíduos amostrados, e também para a produção de frutos novos para as espécies, reflete a grande importância que a sazonalidade pluvial exerce sobre a retomada do crescimento na camada herbácea-subarbustiva de campo sujo de cerrado.
A floração no campo sujo da Fazenda Água Limpa seguiu um padrão similar ao descrito em trabalhos realizados para a comunidade herbácea-subarbustiva de campo sujo no Triângulo Mineiro (A.A.A. Oliveira, dados não publicados) e para áreas de cerrado em São Paulo (Mantovani \& Martins 1988; Batalha et al. 1997; Batalha \& Mantovani 2000), com a floração nas comunidade distribuída por todo o ano, porém com uma diminuição acentuada de produção de flores na estação seca, especialmente nos meses de junho a agosto, e concentração de espécies florescendo na estação chuvosa com pico ocorrendo nos meses de janeiro a abril. Aumentos na precipitação média mensal, temperatura média mensal e fotoperíodo, correlacionaram-se, também, positivamente, com o aumento do número de espécies em floração para o estrato herbáceo-arbustivo no cerrado de Mogi-Guaçu (Mantovani \& Martins 1988). Nas comunidades arbustivo-arbóreas de cerrado encontram-se, também, espécies florescendo ao longo do ano, porém, com picos de floração no final da estação seca e início da chuvosa, principalmente espécies anemocóricas e zoocóricas (Batalha \& Mantovani 2000). No entanto, Gouvea \& Felfilli (1998) observaram uma maior proporção de indivíduos florindo na estação chuvosa em um cerrado sensu stricto em Brasília, quando as espécies muito abundantes floresceram.

Estudos sobre o componente herbáceo e lenhoso de cerrado, conduzidos ao mesmo tempo e na mesma área, demonstram que esse dois estratos têm comportamentos fenológicos diferentes, com as espécies herbáceas com picos de floração do meio para o final da estação chuvosa e as lenhosas com floração mais concentrada no final da estação seca e início da chuvosa (Mantovani \& Martins 1988; Batalha et al. 1997; Batalha \& Mantovani 2000; Batalha \& Martins 2004). Entretanto, investigações de longo prazo que permitam o entendimento da história de vida das espécies de ambos estratos devem ser feitas, visando à obtenção de informações mais precisas sobre os padrões fenológicos que têm sido evidenciados.

Myrcia linearifolia e Vernonia megapotamica apresentaram flores no início do estudo, após o fogo e início das chuvas e, também, no auge da mesma estação. Sarmiento (1992) encontrou dois picos de floração para as espécies de Poaceae Axonopus affinis, A. compressus e A. purpusii, após o fogo em savanas Venezuelanas, sugerindo que este fator estimula a floração.

Verificou-se que a grande maioria dos indivíduos de uma espécie tendem a apresentar os eventos fenológicos concentrados em um período, porém em 
algumas espécies alguns indivíduos florescem ou frutificam em épocas próximas, porém distintas do pico de registro da fenofase, o que confere características diferenciadas entre a fenologia qualitativa e quantitativa da comunidade. Espécies como Andropogon leucostachyus, Axonopus brasiliensis e Eriope complicata, entre outras, foram coletadas férteis nos levantamentos florísticos quinzenais realizados na área durante um ano de trabalho, em épocas diferentes dos seus registros nos levantamentos fenológicos, o que mostra que algumas espécies têm estratégias diferenciadas de estabelecimento no tempo e no espaço, aumentando assim a sua amplitude de produção de novos diásporos, e a oportunidade de superar dificuldades como, por exemplo, uma estação seca muito prolongada.

Foi observada uma tendência mais quantitativa do que qualitativa da influência do fogo na floração e na frutificação na comunidade amostrada na Fazenda Água Limpa, queimada três meses antes no início desse trabalho. O incêndio promoveu a floração de um maior número de indivíduos. Porém, não se observou diminuição na quantidade de espécies florescendo para o mesmo período de um ano para o outro, pois enquanto algumas espécies floresceram somente após o evento do fogo, outras o fizeram no período que não se registrou queimadas. Andropogon bicornis, Bulbostylis paradoxa, Cuphea linarioides, Habenaria nasuta $\mathrm{e}$ Leptocoryphium lanatum, floresceram somente após o incêndio. $\mathrm{O}$ fogo pode ter estimulado essas espécies a florescerem mais cedo na comunidade e a ausência de floração no ano seguinte, isento de incêndios, pode sugerir que elas são pirófilas (Coutinho 1977). Por outro lado, estas podem apresentar padrão bianual ou um intervalo maior entre eventos reprodutivos, merecendo uma investigação de longo prazo. O comportamento reprodutivo de algumas gramíneas muda após o fogo: algumas espécies são altamente dependentes do fogo e muito poucas florescem quando a savana não é queimada (Sarmiento 1992; Canales et al. 1994). Estudos em áreas de campo sujo de cerrado sujeitas a queimadas periódicas demonstram que o fogo atua sobre a biologia das espécies, estimulando a produção de flores e frutos (H.L. César, dados não publicados; Silva et al. 1996). São necessárias investigações de maior tempo para se concluir sobre a influência do fogo nesse componente, e, também, sobre variações na floração dentro de populações entre anos distintos.

O período de produção de frutos novos foi, também, maior no período chuvoso, o que sugere que a falta de chuvas pode ser um fator limitante para a maioria das espécies nesse ambiente. Porém, observou- se frutos novos até o final do mês de julho em indivíduos de Ruellia brevicaulis, Eringium juncifolium, Croton goyazensis, Dalechampia caperonioides, Mimosa lanuginosa e Eriope complicata. Essas plantas também dispersaram suas sementes no final da seca.

A maioria das espécies do campo sujo estudado amadureceram seus diásporos do meio da estação chuvosa até o final da seca. As espécies que dispersam as suas sementes no final da estação seca têm o benefício da umidade das primeiras chuvas. O tempo que uma planta emerge do solo é determinante do sucesso da sua sobrevivência. Assim, uma plântula que emerge logo no início das chuvas tem o benefício de uma longa estação de crescimento. Em adição a isso, existe a ausência temporária de competição, que pode ser acentuada com o progresso da estação (Ross \& Harper 1972).

Gouvea \& Felfili (1998), estudando espécies lenhosas em uma área de Mata de Galeria e uma de cerrado sensu stricto, no Brasil Central, encontraram que no primeiro ambiente, onde há uma maior umidade no solo, a floração e a fruticação estão mais distribuídas ao logo do ano, enquanto que em cerrado as espécies mais abundantes florescem na estação chuvosa e frutificam na seca. A análise fenológica de frutificação da comunidade arbustivo-arbórea de cerrado apresenta um padrão diferenciado de frutificação das espécies por síndromes de dispersão, sendo que de maio a julho encontram-se as maiores taxas de espécies autocóricas e anemocóricas frutificando, enquanto que as zoocóricas têm seu pico de frutificação em outubro, no início das chuvas (Mantovani \& Martins 1988; Batalha et al. 1997; Oliveira 1998). Padrão semelhante foi, também, observado por M.F.L. Souza (dados não publicados), estudando chuva de sementes em comunidades arbustivo-arbóreas de campo sujo e de cerrado em Brasília. Para o componente herbáceo de uma área de cerrado, no estado de São Paulo, Batalha \& Mantovani (2000) observaram padrões semelhantes de frutificação por síndrome de dispersão.

Assim como, para a floração o fogo estimulou, também, a frutificação no campo sujo da Fazenda Água Limpa. Silva \& Ataroff (1985), estudando gramíneas nas savanas Venezuelanas, observaram diferenças significativas no investimento reprodutivo entre dois anos estudados, com e sem fogo. Conforme Coutinho (1982), repetidas observações em áreas queimadas em campo cerrado mostram que a incidência de fogo promove a deiscência de frutos e dispersão de sementes de algumas espécies herbáceas e subarbustivas, e que o aumento da temperatura pode favorecer a germinação de algumas 
espécies do cerrado. No entanto, L.M. Parron (dados não publicados) em um cerrado sensu stricto na Reserva Ecológica do IBGE próxima da FAL, observou que Echinolaena inflexa produziu duas vezes mais sementes em uma área protegida do que em uma área queimada, enquanto Miranda \& Klink (1996) observaram um aumento no investimento na reprodução sexuada para essa espécie na área queimada. Felfili et al. (1999) encontraram uma redução na frutificação de Stryphnodendron adstringens (Mart.) Cov., uma espécie arbórea de cerrado, nos dois anos posteriores a ocorrência de um incêndio em relação aos dois anos anteriores a esse evento.

Na comunidade de campo sujo estudada observouse que no ano em que ocorreu o incêndio houve um menor número de espécies com folhas novas, comparado com o mesmo período do ano seguinte. Possivelmente o fogo retardou o desenvolvimento das folhas em algumas espécies, como Echinolaena inflexa, Borreria poaya e Palicourea coriacea, por exemplo.

Muitas espécies permanecem com as folhas secas na planta, como foi demonstrado pelo aumento de espécies com folhas secas no período chuvoso de 2000 em relação ao de 1999 que ocorreu a queimada, e houve o consumo da massa seca acumulada no estrato herbáceo-subarbustivo. Muitas espécies do estrato herbáceo-subarbustivo do campo sujo da FAL não secaram completamente a parte aérea na estação seca. Estudos detalhados sobre a longevidade e tempo de dessecamento das folhas desse componente são necessários para o perfeito entendimento dos ciclos de vidas das espécies da camada rasteira.

Os ritmos fenológicos na comunidade herbáceasubarbustiva de campo sujo mostraram-se sazonais. Considerando a existência de sincronização da floração das espécies desse ambiente com a estação úmida e com a maturação e dispersão dos frutos na seca. Portanto, a sazonalidade pluviométrica é um dos fatores preponderantes nesse componente.

\section{Agradecimentos}

As autoras agradecem à Kennya Mara Oliveira Ramos e a Newton Rodrigues, pelo apoio e auxílio no trabalho de campo; à CAPES, pela bolsa de Doutorado concedida para a primeira autora; ao DFID-UK, PRONEX-2 e CNPq-PELD, pelo apoio financeiro que permitiu consolidar a infra-estrutura necessária para a execução deste projeto.

\section{Referências bibliográficas}

Almeida, S.P. 1995. Grupos fenológicos da comunidade de gramíneas perenes de um campo cerrado no Distrito $\mathrm{Fe}$ deral, Brasil. Pesquisa Agropecuária Brasileira 30(8): 1067-1073.

Alvim, P.T. 1967. Periodicidade de crescimento das árvores em climas tropicais. Pp. 405-422. In: Anais do XV Congresso Nacional de Botânica. Sociedade Botânica do Brasil.

Barros, M.A.G. \& Caldas, L.S. 1980. Acompanhamento de eventos fenológicos apresentados por cinco gêneros nativos do cerrado (Brasília - Distrito Federal). Brasil Florestal 42: 7-14.

Batalha, M.A.; Aragaki, S. \& Mantovani, W. 1997. Variações fenológicas das espécies do Cerrado em Emas (Pirassununga, SP). Acta Botanica Brasilica 11:61-78.

Batalha, M.A. \& Mantovani, W. 2000. Reproductive phenological patterns of cerrado plant species at the Pé-de-Gigante Reserve (Santa Rita do Passa Quatro, SP, Brazil): a comparasion between herbaceous and wood floras. Revista Brasileira de Biologia 60(1): 129-145.

Batalha, M.A. \& Martins, F.R. 2004. Reproductive phenology of the cerrado plant community in Emas National Park. Australian Journal of Botany 52(2): 149-161.

Borchert, R. 1999. Climatic periodicity, phenology and cambium activity in tropical dry forest trees. IAWA Journal 20(3): 239-247.

Canales, J.; Trevisan M.C.; Silva, J.F. \& Caswell, H. 1994. A demographic study of an annual grass (Andropogon brevifolius Schwarz) in burnt and unburnt savanna. Acta Oecologica 15(3): 261-273.

Coutinho, L.M. 1977. Aspectos ecológicos do fogo no cerrado. II. As queimadas e a dispersão em algumas espécies anemocóricas do estrato herbáceo sub-arbustivo. Boletim de Botânica da Universidade de São Paulo 5 : 57-64.

Coutinho, L.M. 1982. Ecological effect of fire in Brazilian cerrado. Pp. 273-291. In: B.J. Huntley \& B.H. Walker (orgs.). Ecology of tropical savannas. Berlin, SpringerVerlag.

Daubenmire, R. 1972. Phenology and other characteristics of tropical semi-deciduous forest in North-Western Costa Rica. Journal of Ecology 60(1): 147-170.

Eiten, G. 1992. Formas de crescimento das plantas vasculares. Pp. 6-13. In: M.A.G. Barros (org.). Boletim Informativo do Herbário da Universidade de Brasília. Brasília, Universidade de Brasília.

Felfili, J.M.; Silva-Júnior, M.C.; Dias, B.J. \& Rezende, A.V. 1999. Estudo fenológico de Stryphnodendron adstringens (Mart.) Coville no cerrado sensu stricto da Fazenda Água Limpa no Distrito Federal, Brasil. Revista Brasileira de Botânica 22(1): 83-90.

Frankie, G.W.; Baker, H.G. \& Opler, P.A. 1974. Tropical plant phenology: applications for studies in community ecology. Pp. 287-296. In: H. Lieth (org.). Phenology and seasonally modeling. Berlin, Springer-Verlag.

Frankie, G.W.; Baker, H.G. \& Opler, P.A. 1976. Foraging behaviour of solitaries bees: implications for outcrossing of a neotropical forest trees species. Journal of Ecology 64(3): 1049-1057. 
Gouveia, G.P. \& Felfili, J.M. 1998. Fenologia da comunidades de cerrado e mata de galeria no Brasil Central. Revista Árvore 22(4): 443-450.

Gottsberger, G. 1986. Some pollination strategies in neotropical savannas and forests. Plant Systematic and Evolution 152: 29-45

Janzen, D.H. 1967. Synchronization of sexual reproduction of trees within the dry season in Central America. Evolution 21: 620-637.

Madeira, J.A. \& Fernandes, W. 1999. Reproductive phenology of sympatric taxa of Chamaecrista (Leguminosae) in Serra do Cipó, Brasil. Journal of Tropical Ecology 15: 463-479

Mantovani, W. \& Martins, F.R. 1988. Variações fenológicas das espécies do Cerrado da Reserva Biológica de MogiGuaçu, estado de São Paulo. Revista Brasileira de Botânica 23: 227-237.

Miranda, H.S. \& Klink, C.A. 1996. Proteção contra o fogo e seu efeito na distribuição e composição de espécies de cinco fisionomias de cerrado. Pp. 37-45. In: H.S. Miranda; C.H. Saito \& B.F.S. Dias (orgs.). Impactos de queimadas em áreas de cerrado e restinga. Brasília, Universidade de Brasília.

Miranda, I.S. 1995. Fenologia do estrato arbóreo de uma comunidade de cerrado em Alter-do-Chão, PA. Revista Brasilileira de Botânica 18(2): 235-240

Monasterio, M. \& Sarmiento, G. 1976. Phenological strategies of plant species in tropical savanna and the semi-deciduous forest of the Venezuelan Llanos. Journal of Biogeography 3: 325-356.

Oliveira, P.E. 1994. Aspectos da reprodução de plantas de cerrado e conservação. Boletim do Herbário Ezechias Paulo Heringer 1: 34-45

Oliveira, P.E. 1998. Fenologia e biologia reprodutiva das espécies de cerrado. Pp. 169-192. In: S.M. Sano \& S.P. Almeida (orgs.). Cerrado Ambiente e Flora. Brasília, EMBRAPA-CPAC.

Oliveira, P.E. \& Moreira, A.G. 1992. Anemocoria em espécies de cerrado e mata de galeria de Brasília, Distrito Federal. Revista Brasilileira de Botânica 15: 163-174.

Rathcke, B. \& Lacey, E.P. 1985. Phenological patterns of terrestrial plants. Annual Review of Ecology and Systematics 16: 179-214.
Reich, P.W. \& Borchert R. 1984. Water stress and tree phenology in a tropical dry forest in the lowlands of Costa Rica. Journal of Ecology 72: 61-74.

Ribeiro, J.F.; Gonzales, M.I. \& Oliveira, P.E. 1982. Aspectos fenológicos de espécies nativas do cerrado. Pp. 181-198. In: Anais do XXXIII Congresso Nacional de Botânica. Teresina, Sociedade Botânica Brasílica

Ross, M.A. \& Harper, J.L 1972. Occupation of biological space during seedling establishment. Journal Ecology 60: $77-88$.

Sarmiento, G. 1983. The savannas of tropical America. Pp. 245-288. In: F. Bourlière (org.). Ecosystems of the world: tropical savannas. Amsterdam, Elsevier.

Sarmiento, G. 1984. The Ecology of Neotropical Savannas. Cambridge, Harvard University Press.

Sarmiento, G. 1992. Adaptive strategies of perennial grasses in South American savannas. Journal of Vegetation Science 3 : 325-336.

Sarmiento, G. \& Monasterio, M. 1983. Life forms and phenology. Pp. 79-108. In: F. Bourlière (org.). Ecosystems of the world: tropical savannas. Amsterdan, Elsevier.

Schaik, C.P. van; Terborgh, J.W. \& Wright, S.J. 1993. The phenology of tropical forests: adaptative significance and consequences for primary consumers. Annual Review of Ecology and Systematics 24: 353-77.

Seghieri, J.; Floret, Ch. \& Pontanier, R. 1995. Plant phenology in relation to water availability: herbaceous and woody species in the savannas of northern Cameroon. Journal of Tropical Ecology 11: 237-254.

Silva, D.M.S.; Hay, J.D. \& Morais, H.C. 1996. Sucesso reprodutivo de Byrsonima crassa (Malpighiaceae) após uma queimada em um cerrado de Brasília-DF. Pp. 122-127. In: H.S. Miranda; C.H. Saito \& B.F.S. Dias (orgs.). Impactos de queimadas em áreas de cerrado e restinga. Brasília, Universidade de Brasília.

Silva, J.F. 1987. Responses of savannas to stress and disturbance: species dynamics. Pp.141-156. In: B.H. Walker (org.). Determinants of tropical savannas. Paris, IUBS.

Sokal, R.R. \& Rohlf, F.J. 1981. Biometria. 2 ed. Madrid, H. Blume. 